\title{
Effects of Ti, Ti6Al4V, and Ti6Al7Nb on Osteoblast Bioactivity
}

\author{
Jingying Zhang \\ School of Medicine \\ Dalian University \\ E-mail:jingyingzhang2014@foxmail.com
}

\begin{abstract}
The aim of this study was to investigate the surface morphology, hydrophilicity, and effects of sandblasted and acid-etched Ti, Ti6Al4V, and Ti6Al7Nb on the bioactivity of osteoblasts. The surfaces of Ti, Ti6Al4V, and $\mathrm{Ti6} \mathrm{Al} 7 \mathrm{Nb}$ were treated with $\mathrm{Al}_{2} \mathrm{O}_{3}$ sandblasting and a hydrochloric acid-sulfuric acid mixture to create etching. Surface morphology of samples was observed using scanning electron microscopy. The size of the contact angle was measured under a microscope using a measuring instrument. Osteoblasts from Sprague-Dawley rats were inoculated onto the surfaces of Ti, Ti6Al4V, and Ti6Al7Nb at a density of $1 \times 10^{4} \mathrm{cells} / \mathrm{ml}$. Cell morphology was observed using scanning electron microscopy. After sandblasting and acid etching, the surfaces of $\mathrm{Ti}$, Ti6Al4V, and Ti6Al7Nb presented micron-size porous morphology and were hydrophilic. Cells spread significantly on the sandblasted and acid-etched surfaces of all three surfaces. Adhesion of osteoblasts was strongest on the surface of Ti6Al7Nb. Sandblasting and acid etching promoted bioactivity on all three surfaces, although sandblasted and acid-etched Ti6Al7Nb showed better bioactivity than Ti or Ti6Al4V. Overall, osteoblasts on the surface of Ti6Al7Nb exhibited better adhesion.
\end{abstract}

Keywords-Ti;Ti6Al4V;Ti6Al7Nb; sandblasting and acid etching;bioactivity

\section{INTRODUCTION}

Materials science and oral medicine have undergone rapid development in recent years, with widespread dissemination of immediate implant technology. These factors have resulted in implants and repairs being the preferred methods for treating dentition defects and replacing missing dentition. Titanium and titanium alloys have become major implant materials because of their good mechanical properties and biocompatibility ${ }^{[1]}$. Superior bioactivity and hydrophilicity on the implant surface are important qualities that enhance rapid osseointegration $^{[2]}$. Scholars have investigated many surface modification methods, including titanium plasma coating, hydroxyapatite coating, micro-arc oxidation, and plasma spraying ${ }^{[3,4]}$. Each method has its advantages and disadvantages according to its materials and processes. Sandblasting and acid etching have achieved a high success rate clinically. It is a simple, stable technique ${ }^{[5]}$. It is thus considered a proven, reliable method for surface treatment. With the now extensive application of pure $\mathrm{Ti}$ implants, however, some shortcomings have appeared, such as the low intensity of pure $\mathrm{Ti}$, poor abrasion capability, easy oxidation in air, and gingival darkening. Ti alloys give superior performance by regulating the proportion of elements: They are strong, are highly resistant to corrosion, and have a low modulus of elasticity. Ti6Al4V and Ti6Al7Nb are titanium alloys that are extensively applied in aviation, aerospace, and medicine.

In this study, sandblasting and acid etching were used on the surfaces of Ti, Ti6Al4V, and Ti6Al7Nb. The surface morphology, hydrophilicity and biocompatibility of sandblasted and acid-etched $\mathrm{Ti}$, Ti6Al4V, and Ti6Al7Nb were compared to evaluate their suitability as implant material with good mechanical properties and bioactivity.

\section{MATERIALS AND METHODS}

\section{A. Sample preparation}

We used commercial pure Ti (purity 99.99\%), Ti6Al4V, and Ti6Al7Nb. The surfaces of samples were ground and polished using No. 400, 600, 800, and 1500 $\mathrm{SiC}$ sandpaper as a mirror surface. They then underwent ultrasonic cleaning with $100 \%$ acetone, $100 \%$ ethanol, and deionized water for 15 minutes. All samples were oven-dried. They were then shaped into round specimens of $15 \mathrm{~mm}$ diameter and $1 \mathrm{~mm}$ thick and placed in an oven at room temperature for further use.

All samples were sandblasted with an inhaled dry blasting machine (JY-80D, Jiuye Machinery Manufacture Co., LTD, Beijing, China) under the following conditions: The abrasive material was $250-300 \mu \mathrm{m}$ of corundum sand (particle size \#60); air pressure was $0.2 \mathrm{MPa}$, time was 30$60 \mathrm{~s}$, sandblasting angle was $75^{\circ}$. After sandblasting, the samples were washed with ethanol and deionized water using ultrasonic cleaning for 10 minutes. They were ovendried.

For acid etching, $\mathrm{HCl}, \mathrm{H} 2 \mathrm{SO} 4$, and $\mathrm{H} 2 \mathrm{O}$ were mixed in proportions of 11:12:2 and heated to boiling. The samples were placed in $50 \mathrm{C}$ distilled water for $2 \mathrm{~min}$ and then etched in the boiling etching solution for 60-80 seconds. During immersion in the etching solution, bubbles appeared on the surfaces of samples, which increased with the duration of the etching process. When the etching solution changed from colorless to purple, the samples were immediately removed, washed with deionized water using ultrasonic cleaning for $10 \mathrm{~min}$, and then oven-dried. The parameters for $\mathrm{Ti}$, Ti6Al4V, and Ti6Al7Nb are shown in TABLE I.

\section{B. Analysis of the sample surface}

Surface morphologies of Ti, Ti6Al4V, and Ti6Al7Nb were analyzed using ultra-high resolution field emission scanning electron microscopy (NOVA NanoSEM450; FEI, Hillsboro, OR, USA) before and after sandblasting and 
acid etching. Samples were placed on the frame of highspeed video optical contact angle measuring instrument (OCAH200; FDS, Garden City, NY, USA). Distilled water
(4 $\mu$ l) was slowly dropped on the center of the sample's surface. The size of the contact angle was measured under the

microscope.

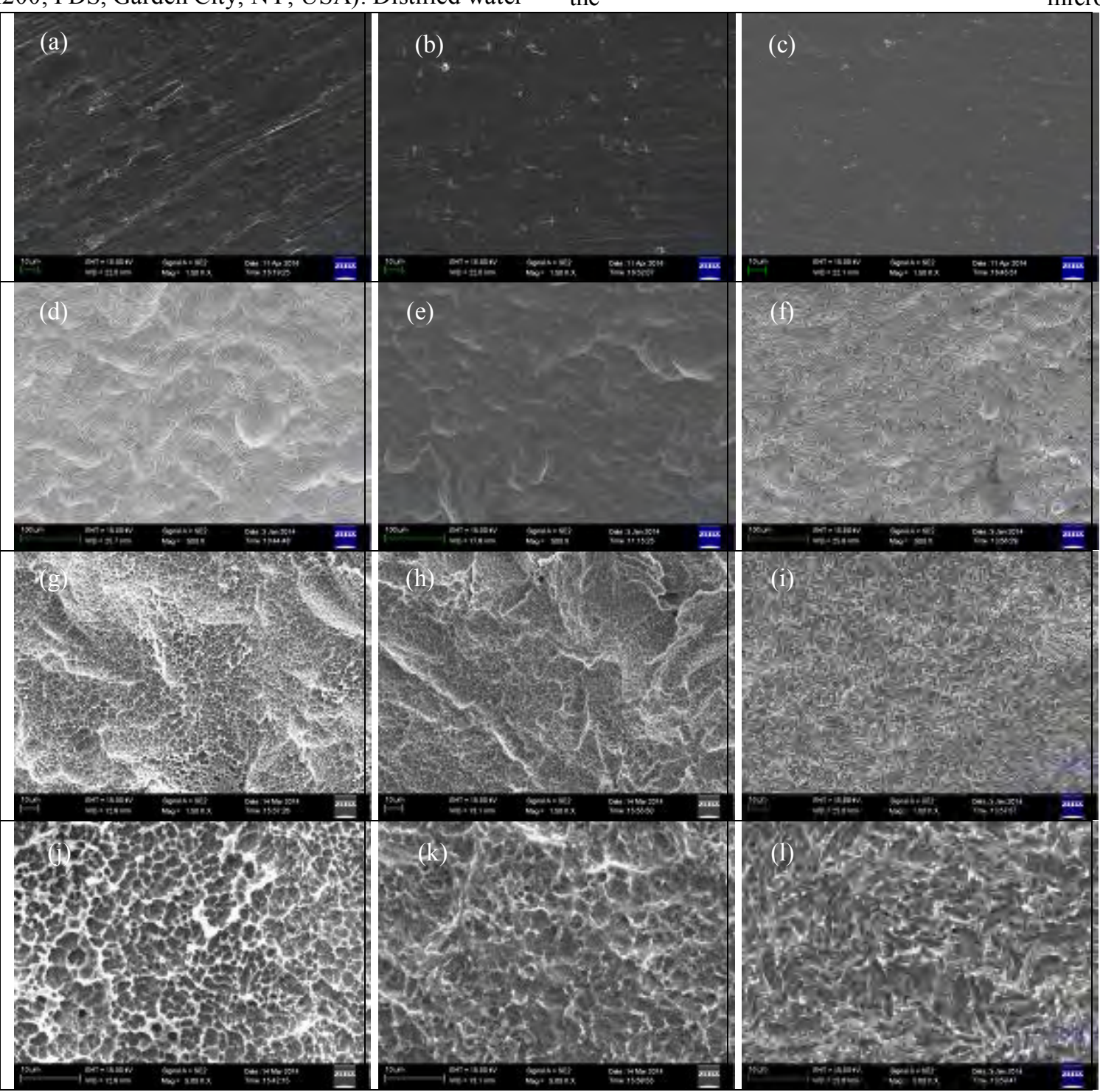

Figure 1. Micrographs of samples before and after sandblasting and acid etching as seen by scanning electron microscopy. a Polished Ti. b Polished Ti6Al4V. c Polished Ti6Al7Nb. d, g, j Sandblasted and acid-etched Ti. e, h, k Sandblasted and acid-etched Ti6Al4V. f, i, 1 Sandblasted and acid-etched $\mathrm{Ti} 6 \mathrm{~A} 17 \mathrm{Nb}$

\section{Biological activity tests}

\section{1) Culture of primary cells}

Neonatal Sprague-Dawley rats were sacrificed by breaking their necks. They were sterilized with $75 \%$ alcohol for 5 min and then washed with D-Hank's solution. Cranial bone was isolated before the periosteum and connective tissue were removed. The skull bone was washed with Dulbecco's Modified Eagle's Medium (DMEM) and cut into pieces. The pieces were then digested with $0.25 \%$ trypsin at $37 \mathrm{C}$ for $20 \mathrm{~min}$. After removing the trypsin solution, the pieces were digested with type II collagenase $(1 \mathrm{mg} / \mathrm{mL})$ at $37 \mathrm{C}$ for $20 \mathrm{~min}$ and then centrifuged. Following removal of the collagenase solution, the pieces were incubated with DMEM containing $15 \%$ serum and agitated. This cell suspension was incubated in a culture flask and placed in a $37 \mathrm{C} \mathrm{CO}_{2}$ thermostatic incubator.

\section{2) Cell morphology}

$\mathrm{Ti}$, Ti6Al4V, and Ti6Al7Nb samples were separately placed in sterile 24-well plates (4 pieces each). The osteoblast suspension $(100 \mu \mathrm{L})$ at a density of $1 \times 10^{4}$ cells $/ \mathrm{mL}$ was placed on the surface of each sample for 24 and 48 hours. Samples were washed with PBS (0.1 mol/L), fixed in $2.5 \%$ glutaraldehyde for $24 \mathrm{~h}$ at $4 \mathrm{C}$, washed twice with $\mathrm{PBS}$ for $10 \mathrm{~min}$ each time, fixed in $4 \mathrm{C}$ precooled $1 \%$ osmic acid for $1 \mathrm{~h}$ at $4 \mathrm{C}$, followed by two 10-min washes with PBS. Samples were then dehydrated through a graded alcohol series, dried, and sprayed with $\mathrm{CO}_{2}$ at the critical point. Cell morphology on the surfaces of materials was observed and photographed using scanning electron microscopy (NOVA NanoSEM450). 


\section{RESULTS AND DISCUSSION}

\section{A. Surface morphology of samples}

Macroscopic observation showed that following sandblasting and acid etching, the surfaces of Ti, Ti6Al4V, and $\mathrm{Ti} 6 \mathrm{Al} 7 \mathrm{Nb}$ were smooth, had no metallic luster, and were dark gray. The surface morphology of samples observed by scanning electron microscopy is shown in Fig .1. After mechanical polishing, scratches in the same direction were visible on the surfaces of Ti, Ti6Al4V, and Ti6Al7Nb. Micron-size holes (first class holes) with apertures of $80-90 \mu \mathrm{m}$ and small holes (second class holes) with apertures of $2-8 \mu \mathrm{m}$ were observed on the surfaces of the samples. First class holes were shallowly concave, circular, or elliptical and were connected into a film. Second class holes were round or oblong with a sharp edge and regular size and shape. Acid etching removed residual blasting particles on the sample surfaces. They not only retained large concavities (first class holes) formed by sandblasting but also increased the small concavities (second class holes) formed by acid etching and optimized the ultrafine pore structure on the surface of the implant. A previous study confirmed that porous surface morphology, from microns to nanometers, contributed to $\mathrm{Ca}$ and $\mathrm{P}$ deposition and osteoblast adhesion, proliferation, and growth on the implant surface ${ }^{[6]}$. It also promoted the formation of mechanical locks between bone tissue and the implant surface ${ }^{[7]}$. Semicircular holes and apertures of 1-5 $\mu \mathrm{m}$ were beneficial to the implant's osseointegration ${ }^{[8]}$. In this study, the honeycomb of micron holes formed on the surfaces of $\mathrm{Ti}, \mathrm{Ti} 6 \mathrm{Al} 4 \mathrm{~V}$, and $\mathrm{Ti} 6 \mathrm{Al} 7 \mathrm{Nb}$ caused by the sandblasting and acid etching increased the bioactivity of titanium implants.

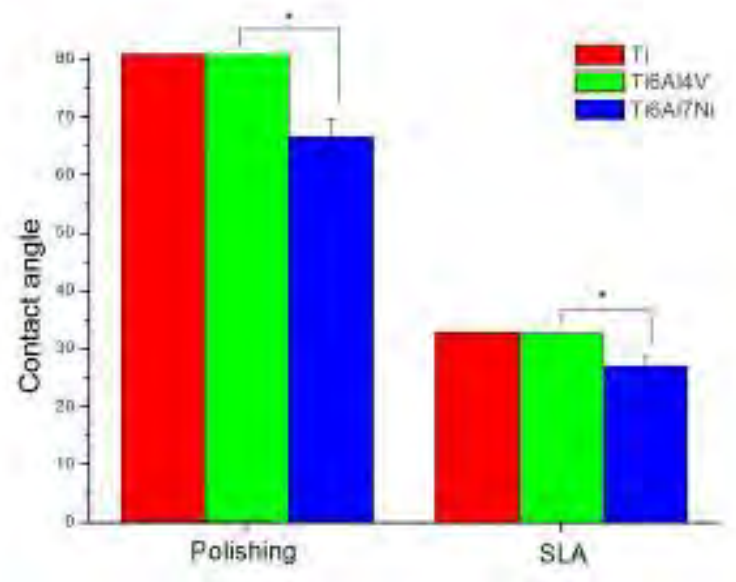

Figure 2. Contact angles of samples after polishing and sandblasting and acid etching (SLA)

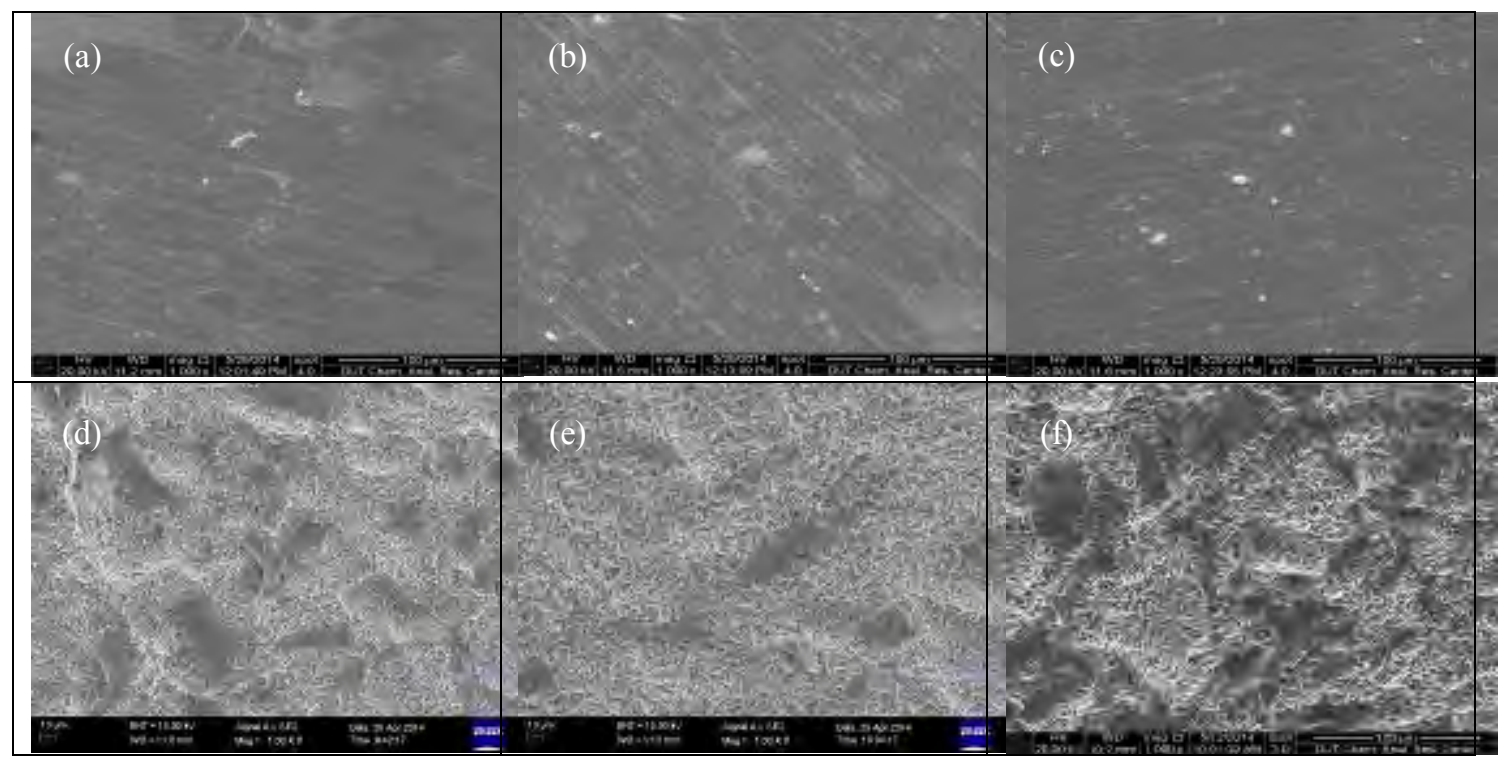

Figure 3. Morphology of osteoblasts before and after sandblasting and acid etching. a Polished Ti. b Polished Ti6Al4V. c Polished Ti6Al7Nb. d Sandblasted and acid-etched Ti. e Sandblasted and acid-etched Ti6Al4V. f Sandblasted and acid-etched Ti6Al7Nb 


\section{B. Contact angle of the surface}

Hydrophilicity, which is an important factor in surface wettability, can be expressed as the contact angle. Acute and obtuse angles, respectively, reflect wetting and nonwetting states. Fig .2 shows the contact angles of sandblasted and acid-etched $\mathrm{Ti}$, Ti6Al4V, and Ti6Al7Nb and the Ti alloy-distilled water surface. After sandblasting and acid etching, the contact angle on the sample surface decreased, and surface energy increased. Factors affecting the contact angle and the surface energy on a sample's surface are mainly the hydrophilicity of the chemical composition of the material surface and the roughness of the sample's surface. Previous studies demonstrated that no significant differences in surface roughness (Ra) were observed among three samples after sandblasting and acid etching: Ti $(\mathrm{Ra}=2.73)$; Ti6Al4V $(\mathrm{Ra}=3.2)$; Ti6Al7Nb $(\mathrm{Ra}=3.2)$. Therefore, the main factor in the strong hydrophilicity of the Ti6Al7Nb surface was its unique alloy composition. The hydrophilicity of Ti6Al7Nb was better than that of $\mathrm{Ti}$, which could elevate cell adhesion and protein-binding probability on a $\mathrm{Ti}$ implant surface, and the success rate of implant osseointegration.

\section{Cell morphology}

As displayed in Fig .3, the numbers of osteoblasts that adhered to the sandblasted and acid-etched surfaces of $\mathrm{Ti}$, Ti6Al4V, and Ti6Al7Nb were obviously higher than on the mechanically polished surfaces. Cells on the mechanically polished surfaces were spherical or polygonal, without obvious extension, whereas cells on sandblasted and acid-etched surfaces extended in various directions. They had fusiform, polygonal, and irregular shapes, were plump, and had many cell matrices. With the help of extracellular matrix proteins, the extended pseudopodia adhered to the sample surface, spread on the surface of porous samples, grew onto surrounding pores, and became tightly adherent to the sample's surface.

\section{CONCLUSION}

Sandblasting and acid etching were utilized to cause micron-size porous morphology on the surfaces of $\mathrm{Ti}$, Ti6Al4V, and Ti6Al7Nb. The adhesion of osteoblasts were noticeably increased on the sandblasted and acid-etched surfaces of Ti, Ti6Al4V, and Ti6Al7Nb. Following this etching process, $\mathrm{Ti} 6 \mathrm{Al} 7 \mathrm{Nb}$ was better than $\mathrm{Ti}$ and Ti6Al4V for promoting osteoblast proliferation and differentiation and enhanced bioactivity. Taken together, sandblasted and acid-etched Ti6Al7 $\mathrm{Nb}$ is expected to be a dental implant material with a low modulus of elasticity and good bioactivity.
TABLE I.

PARAMETER OF SAMPLE PREPARATION

\begin{tabular}{|c|c|c|c|c|}
\hline \multirow[t]{2}{*}{ Group } & \multicolumn{4}{|c|}{ Parameter of SLA } \\
\hline & $\begin{array}{c}\text { Intensity of pr } \\
\text { essure }\left(\mathrm{Al}_{2} \mathrm{O}_{3}\right. \\
\text { particles sand } \\
\text { blasting) }\end{array}$ & $\begin{array}{l}\text { Time of } \\
\text { sand } \\
\text { blasting }\end{array}$ & $\begin{array}{c}\text { Acid etching } \\
\text { liquid(Volume } \\
\text { ratio) } \\
\left(\mathrm{H}_{2} \mathrm{O}: \mathrm{H}_{2} \mathrm{SO}_{4}\right. \\
\quad: \mathrm{HCL})\end{array}$ & $\begin{array}{c}\text { Time } \\
\text { of } \\
\text { acid et } \\
\text { ching }\end{array}$ \\
\hline $\mathrm{Ti}$ & $0.2 \mathrm{MP}$ & $30 \mathrm{~s}$ & $11: 12: 2$ & $80 \mathrm{~s}$ \\
\hline Ti6Al4V & $0.2 \mathrm{MP}$ & $60 \mathrm{~s}$ & $11: 12: 2$ & $60 \mathrm{~s}$ \\
\hline Ti6Al7Ni & $0.2 \mathrm{MP}$ & $30 \mathrm{~s}$ & $11: 12: 2$ & $80 \mathrm{~s}$ \\
\hline
\end{tabular}

\section{ACKNOWLEDGMENT}

The Liaoning Province Department of Education Foundation in China (2013481), Dalian Science and Technology Project in China (2013E11SF057), China Postdoctoral Science Foundation (2014M551097), and Liaoning Province Postdoctoral Start Foundation in China (20141198) supported this study.

We are grateful to SUNTEC Titanium Co., Ltd., Dalian, Liaoning Province, China for providing titanium and titanium alloy materials.

\section{REFERENCES}

[1] Feller L, Chandran R, Khammissa RA, Meyerov R, Jadwat Y, Bouckaert M, Schechter I, Lemmer J. Osseointegration: biological events in relation to characteristics of the implant surface. SADJ.2014,69(3),pp.114-7.

[2] Sjöström T, Brydone AS, Meek RM, Dalby MJ, Su B, McNamara LE. Titanium nanofeaturing for enhanced bioactivity of implanted orthopedic and dental devices. 2013,8(1),pp.89-104.

[3] Förster Y, Rentsch C, Schneiders W, Bernhardt R, Simon JC, Worch H, Rammelt S. Surface modification of implants in long bone. Biomatter. 2012,2(3),pp.149-57.

[4] Neoh KG, Hu X, Zheng D, Kang ET. Balancing osteoblast functions and bacterial adhesion on functionalized titanium surfaces. Biomaterials. 2012,33(10),pp. 2813-22

[5] Nasatzky E, Gultchin J, Schwartz Z. The role of surface roughness in promoting osteointegration. Refuat Hapeh Vehashinayim. 2003, 20(3), pp.8-19

[6] Liang C, Wang H, Yang J, Cai Y, Hu X, Yang Y, Li B, Li H, Li H, $\mathrm{Li} C$, Yang $\mathrm{X}$. Femtosecond laser-induced micropattern and $\mathrm{Ca} / \mathrm{P}$ deposition on $\mathrm{Ti}$ implant surface and its acceleration on early osseointegration. ACS Appl Mater Interfaces, 2013,28,5(16), pp. 8179-86.

[7] Goto T. Osseointegration and dental implants. Clin Calcium, .2014, 24(2), pp. 265-71.

[8] Hansson S, Löberg J, Mattisson I, Ahlberg E. Global biomechanical model for dental implants. J Biomech, 2011,7,44(6), pp.1059-65.

[9] Stockert JC, Blázquez-Castro A, Cañete M, Horobin RW, Villanueva A. MTT assay for cell viability: Intracellular localization of the formazan product is in lipid droplets, 2012,114(8), pp.785-96.

[10] Su B, Li JD, Jiang DM, Li YB, Qiao B, Li WC. In vivo study on polyurethane/nano-hydroxyapatite/polyamide 66 femoral condyle for repairing articular osteochondral defects for femur in dog. Functional Materials,2013,4(44), pp. 493-497.

[11] Sharma U, Pal D, Prasad R. Alkaline phosphatase: an overview. Indian J Clin Biochem.,2014,29(3),pp.:269-78.

[12] Chen GB, Lv YG, Zhang XM, Dong CJ, Guo P, Yang L. Research progress in decellularized matrix material for tissue engineering. Functional Materials,2013,21(44),pp. 3065-3071. 